\title{
Influència generacional en la gestió de l'empresa familiar
}

\author{
Jordi Moreno Genéa i José Luis Gallizo Larraz ${ }^{b^{*}}$ \\ ${ }^{a}$ Professor lector en el departament d'Administració d'Empreses de la Universitat de Lleida \\ ${ }^{\text {b}}$ Director de la Càtedra d'Empresa Familiar de la Universitat de Lleida \\ *Correu de contacte: jordi.moreno@.udl.cat \\ Rebut 30 de març 2021; Acceptat 15 de juny 2021
}

\begin{abstract}
Resum
L'objectiu del treball és analitzar i comparar les empreses familiars de primera generació amb les de segona i posteriors generacions a través de certes característiques rellevants per a una major comprensió de la influència sobre el negoci d'una transició generacional. Per a això l'estudi examina una mostra de 1.005 empreses familiars espanyoles identificada per l'Institut d'Empresa Familiar d'Espanya que han proporcionat informació sobre la seva estratègia de creixement, govern corporatiu, professionalització, estructura de propietat, finances i resultats. Les dades financeres s'han extret de la base de dades SABI per al període 2016-2020. Els resultats demostren que si bé les diferències quant a rendibilitat són petites entre generacions, si existeixen diferències significatives en diferents àmbits de la gestió que afecten l'acompliment empresarial. El creixement empresarial tendeix a ser inferior en les segones i següents generacions, qui també presenten una major professionalització de la gestió i una major tendència a internacionalitzar-se. També s'observen diferències en quant a l'estructura financera. Els resultats de la recerca poden tenir una importància pràctica en la gestió de la internacionalització, el creixement i la promoció de l'acompliment en l'etapa de successió intergeneracional.
\end{abstract}

Classificació JEL: G31, G32, M10, M14

Paraules Clau: Empresa familiar, diferències intergeneracionals, rendibilitat, CEO, creixement, endeutament, internacionalització.

\section{Introducció}

El canvi generacional en les empreses familiars es dona en un moment crucial en el qual és necessari prendre decisions estratègiques per a enfrontar-se als desafiaments del sector, i també decisions per a preservar l'esperit emprenedor de l'empresari, actualitzar tecnologies i productes de l'organització. Les empreses familiars s'enfronten a desafiaments inevitables pel canvi generacional, desafiaments que un altre tipus 
d'organitzacions no tenen i que es gestionen de manera diferent segons sigui el perfil de cada generació entrant (Jaffe i Lane, 2004).

Els hereus prenen decisions que poden rejovenir l'empresa en la competició amb els seus rivals en el mercat o poden quedar-se sense intervenir en una estratègia intergeneracional (De Clercq i Belausteguigoitia, 2015). En tot cas, cada generació contribueix al patrimoni de coneixements de manera diferent, afectant la capacitat d'innovació de l'empresa familiar. Treballs anteriors han analitzat les relacions entre la successió intergeneracional, l'acompliment i la innovació posant de manifest les dificultats per a innovar en un entorn conservador com és el de les famílies empresàries (Woodfield i Husted, 2019; Yu i Cai, 2017), per això és important comprendre la influència directa de la successió en les relacions personals (Seymour, 1993, Williams et al., 2013). La nostra intenció és contemplar les diferències generacionals en una visió de recursos i capacitats de d'empresa per al seu creixement i internacionalització que quan assumeixen la gestió adopten estratègies innovadores i situacions de risc que impulsen noves oportunitats (Levring i Moskowitz, 1993).

Aquest article analitza i compara les empreses familiars de primera generació amb les de segona i posteriors generacions a través de certes característiques rellevants per a una major comprensió de la influència sobre el negoci d'una transició generacional. Per a això, no sols analitzem les diferències en quant a rendibilitat, sinó que indaguem en els seus orígens per a entendre millor la influència que els diferents estils de gestió de cada generació tenen sobre aquesta.

Analitzem el vincle entre generació familiar i acompliment empresarial sobre una àmplia mostra d'empreses familiars espanyoles utilitzada pel IEF per al període 20162020. La naturalesa inductiva del nostre estudi condueix a una tipologia conceptual que captura els patrons de successió en empreses familiars espanyoles i avalua els seus diversos efectes sobre l'abast de la seva participació internacional. En els resultats s'observa que el creixement empresarial tendeix a ser inferior en les segones i següents generacions, tant en inversions d'immobilitzat com en vendes i que això podria evitar-se aconseguint l'equilibri adequat entre les decisions de transferència de propietat, el desenvolupament al llarg del temps de les pràctiques de gestió adequades i la decisió de professionalitzar les pràctiques de gestió empresarial. Els resultats de la recerca tindrien una importància pràctica en la gestió de la internacionalització, el creixement i la promoció de l'acompliment en l'etapa de successió intergeneracional.

En la següent secció establim la teoria i hipòtesi de treball seguit d'una descripció de la mostra d'empreses i variables utilitzades. A continuació, es descriu la metodologia utilitzada i es presenten els nostres resultats. Finalment, aportem propostes i conclusions amb una discussió de les nostres resultats i les implicacions de l'estudi.

\section{Generacions familiars i estils de gestió}

La successió en l'empresa familiar suposa la transferència de lideratge i control d'una generació a la següent, és un dels temes més investigats en el camp de l'empresa familiar perquè representa un dels desafiaments més importants al que s'enfronten les empreses familiars (Benavides-Velasco et al., 2013). S'ha provat que el relleu generacional és impulsor de noves oportunitats. L'arribada de joves CEOs desencadena en les EF la innovació i les possibilitats d'obtenir avantatges competitius mitjançant l'obertura a l'exterior (Levring i Moskowitz, 1993). 
La teoria de les diferències intergeneracionals va ser proposada pel sociòleg Karl Mannheim, qui va assenyalar que els grups de diferents èpoques tindrien diferències en idees, actituds i comportaments a causa dels seus diferents anys de naixement $\mathrm{i}$ entorns de creixement. Certs autors opinen que esdeveniments històrics i les seves conseqüències tenen influència en la formació de diferències intergeneracionals, inclosos esdeveniments polítics significatius, noves tecnologies d'avanç, transformació i millora de l'economia social i successió i renovació de cultures socials (McCourt, 2012). Quan arriben nous membres familiars a la direcció de l'empresa un canvi d'estratègia és probable que es produeixi (Levring i Moskowitz, 1993).

Alguns autors han obtingut la manera en què els diferents patrons de successió influeixen en aspectes importants de la vida de l'empresa, com l'estratègia i l'acompliment (Miller et al. 2003). Així, els patrons de successió "rebels", que mostren un rebuig a les maneres de dirigir anteriors, tenien més probabilitats de prendre noves iniciatives estratègiques radicals. Per contra, els patrons de successió "conservadors", molt vinculats a les maneres de dirigir el negoci del titular, tenien més probabilitats de prendre iniciatives estratègiques de baix risc. Finalment, els patrons de successió "vacil-lants", que expliquen un desig del successor de deixar la seva petjada en l'empresa, però no està segur de com fer-ho. Aquests patrons identificats per Miller et al. (2003) revelen la naturalesa subjacent de la dinàmica internacional.

Les empreses familiars, com qualsevol empresa, s'enfronten a un mercat dinàmic, global i altament competitiu, que demanda cada vegada més la incorporació de nous productes, noves tecnologies, nous mètodes organitzatius i nous mètodes per a competir en el mercat obert (Galve-Gorriz i Salas-Fumas, 2011). Això significa que les empreses familiars requereixen cert nivell d'inversió/creixement si el seu objectiu és continuar sent competitives i assegurar la seva supervivència a llarg termini, mantenint la propietat i el control de l'empresa dins de la família (Chami, 1999). A més, és probable que les estratègies de creixement, en termes d'internacionalització, comercialització i innovació, siguin impulsades per propietaris de segona o posterior generació pel fet que aporten noves perspectives a la companyia (Fernández i Nieto, 2005). S'entén que és necessari continuar sent competitiu quan l'empresa s'adapta a les necessitats de la família a mesura que altres membres s'incorporen a l'empresa (Gorg, 1988).

En quant al nivell de deute que permeti donar suport al creixement i la internacionalització de l'empresa, hi ha treballs que suggereixen que les empreses que han transferit la propietat a la següent generació amb èxit poden obtenir millors condicions financeres per part dels bancs, la qual cosa podria explicar aquest major increment en els nivells de deute en següents generacions (Gersick et al., 1997). Tal és així que la successió, com a característica única de les organitzacions familiars, pot influir en la internacionalització de les empreses i en el seu creixement (Shi et al., 2019). Treballs previs suggereixen que la presa de possessió dels líders de la pròxima generació pot afectar la internacionalització de l'empresa en influir en l'orientació global, la motivació i el compromís de l'empresa amb la seva sortida a l'exterior (Fang et al., 2018).

La selecció dels membres de la família sovint resulta més complicada que la contractació de professionals externs, com a resultat de la superposició institucional entre la família i l'empresa (Lansberg, 1999). En certs casos la família opta per donar entrada en l'empresa a familiars disposats a treballar, però sense una promoció 
garantida, en altres casos l'empresa familiar segueix una política selectiva, reclutant només a familiars amb potencial d'ascens (Cadbury, 2002), per això, és probable que les empreses de segona generació siguin més grans, més madures i més antigues i generin major rendibilitat.

Sobre la base de la discussió anterior presentem les següents hipòtesis:

\section{H1: La successió intergeneracional té un efecte positiu en la rendibilitat}

H2: Les empreses familiars de segona i següents generacions invertiran més en estratègies de creixement de l'empresa que es manifestarà en un creixement del balanç, de l'estructura fixa de producció i de les vendes.

H3: Les empreses familiars de segona i següents generacions tindran un major nivell de deute que les empreses familiars de primera generació i major internacionalització.

H4: Les empreses familiars de segona i següents generacions seran més professionalitzades, amb un major número de CEO no familiars, i tindran una major capacitat per a contractar, promoure i retenir als millors professionals, que les empreses familiars de primera generació.

\section{Mostra i variables}

Les dades analitzades en aquest estudi corresponen a una mostra de 1.005 empreses familiars espanyoles per al període 2016-2020. La mostra d'empreses utilitzada per a aquest estudi es correspon amb la mostra d'empreses utilitzada en el treball publicat per l'Institut de l'Empresa Familiar (2018). Aquesta mostra es va obtenir d'una mostra inicial més àmplia de 94.565 empreses espanyoles que complien amb la definició d'empresa familiar proposta per l'Institut de l'Empresa Familiar (2015). Aquesta definició, es basa en els percentatges de capital en mans de la família propietària, no obstant això, té en compte que no és adequat aplicar els mateixos percentatges per a totes les empreses, ja que, en empreses amb una propietat més dispersa, no és necessari un percentatge de propietat tan elevat per a exercir el control sobre la companyia. Sobre la base d'aquesta consideració, una empresa adquireix la consideració d'empresa familiar en els següents casos:

- Estructura de propietat dispersa (cap accionista posseeix més del 50\% del capital). L'empresa serà familiar si una persona o família posseeix més d'un $5 \%$ individual o un $20 \%$ en el seu conjunt i a més l'accionista persona física és membre del Consell d'Administració o són accionistes amb més del 20\% del capital i directiu. En cas contrari l'empresa serà classificada com no familiar.

- Estructura de propietat concentrada (algun accionista posseeix més del 50\% del capital). L'empresa serà familiar quan l'accionista familiar controli la propietat amb un percentatge elevat $(50,01 \%)$, o bé en la qual existeixin accionistes-directors amb una participació superior al $50,01 \%$. Sent no familiars les empreses que no compleixin aquest criteri.

Tal com es detalla en Institut de l'Empresa Familiar (2018), la mostra final de 1.005 empreses es va obtenir a través d'una selecció seguint un procediment aleatori sistemàtic de les bases telefòniques existents. Quant a la distribució de la mostra, es va plantejar 
una estratificació de la mostra atesa la comunitat autònoma, grandària de l'empresa i activitat, aconseguint d'aquesta manera una mostra altament representativa del teixit empresarial familiar espanyol.

Les dades econòmiques i financeres de les empreses, s'han obtingut de la base de dades SABI (Sistema d'Anàlisi de Balanços Ibèrics). Mentre que la informació relativa a les característiques de la direcció i gestió de la mateixa es van obtenir a través d'entrevistes telefòniques realitzades al $\mathrm{CEO} \mathrm{o}$ màxim responsable de l'empresa mitjançant qüestionari estructurat.

En la Taula 1 podem observar com es distribueixen les empreses de la mostra per grandària (segons nombre de treballadors) i activitat (NACE-REV. 2):

Taula 1. Distribució d'empreses segons activitat i dimensió.

\begin{tabular}{|l|c|c|c|c|c|}
\hline \multicolumn{1}{|c|}{ ACTIVITAT } & MICRO & PETITA & MITJANA & GRAN & TOTAL \\
\hline Agricultura, ramaderia, silvicultura i pesca & 9 & 18 & 2 & 0 & 29 \\
\hline Indústries extractives & 1 & 3 & 0 & 0 & 4 \\
\hline Indústria manufacturera & 39 & 147 & 25 & 3 & 214 \\
\hline $\begin{array}{l}\text { Subministrament d'energia elèctrica, gas, vapor i } \\
\text { aire condicionat }\end{array}$ & 1 & 1 & 0 & 0 & 2 \\
\hline $\begin{array}{l}\text { Subministrament d'aigua, activitats de sanejament, } \\
\text { gestió de residus i descontaminació }\end{array}$ & 1 & 3 & 1 & 0 & 5 \\
\hline Construcció & 56 & 67 & 6 & 0 & 129 \\
\hline $\begin{array}{l}\text { Comerç a l'engròs i al detall; reparació de vehicles } \\
\text { de motor i motocicletes }\end{array}$ & 118 & 174 & 20 & 0 & 312 \\
\hline Transport i emmagatzematge & 15 & 38 & 5 & 1 & 59 \\
\hline Hostaleria & 12 & 47 & 7 & 1 & 67 \\
\hline Informació i comunicacions & 5 & 13 & 4 & 1 & 23 \\
\hline Activitats financeres i d'assegurances & 3 & 3 & 0 & 0 & 6 \\
\hline Activitats immobiliàries & 9 & 5 & 0 & 0 & 14 \\
\hline Activitats professionals, científiques i tècniques & 13 & 29 & 4 & 0 & 46 \\
\hline Activitats administratives i serveis auxiliars & 9 & 23 & 7 & 2 & 41 \\
\hline Educació & 2 & 7 & 2 & 0 & 11 \\
\hline Activitats sanitàries i de serveis socials & 3 & 12 & 3 & 1 & 19 \\
\hline Activitats artístiques, recreatives i d'entreteniment & 3 & 8 & 1 & 0 & 12 \\
\hline Altres serveis & 3 & 8 & 1 & 0 & 12 \\
\hline TOTAL & 302 & 606 & 88 & 9 & 1.005 \\
\hline
\end{tabular}

Tal com podem observar, la mostra està formada en la seva majoria per petites empreses (entre 10 i 49 treballadors) que representen un 60,30\% del total d'empreses de la mostra. A continuació, se situarien les microempreses (menys de 10 treballadors) que aporten el $30,05 \%$ de les empreses. I amb una menor representació tenim les mitjanes empreses (entre 50 i 249 treballadors) i les grans empreses (més de 250 treballadors) que aporten el $8,76 \%$ i el $0,90 \%$ del total d'empreses, respectivament. En quant als sectors d'activitat, les que compten amb una major representació són "Comerç a l'engròs i al detall; reparació de vehicles de motor i motocicletes" que aporta el 31,04\% de les empreses i la "indústria manufacturera", que aporta el 21,29\%. Més allunyat en pes ja es trobaria la "construcció" $(12,84 \%)$. 
En quant a les variables analitzades en aquest estudi, a més de l'existència de diferències significatives entre les empreses familiars de primera o posteriors generacions en quant a rendibilitat, ens centrarem en les diferències existents en 4 dimensions concretes: Característiques del CEO, Creixement empresarial, Estructura financera $i$ Internacionalització. Concretament, en cadascuna d'aquestes dimensions s'analitzaran diferents variables que ens permetran visualitzar millor les diferències pel que fa a la gestió de les diferents generacions.

En primer lloc, en quant a les característiques del CEO en l'empresa familiar, s'ha tingut en compte l'Origen del CEO. Per a això, s'ha inclòs una variable dicotòmica que pren el valor 1 quan el CEO és un professional extern a la família i 0 quan la persona que dirigeix l'empresa pertany a la família propietària. La naturalesa del CEO pot implicar diferents habilitats de gestió (Finkelstein i Hambrick, 1996) i generar diferents tipus de problemes d'agència (Jensen i Meckling, 1976), la qual cosa sens dubte afectarà l'acompliment de la companyia. Treballs recents com el de Sánchez et al. (2019) ja han mostrat que en empreses familiars cotitzades la presència un CEO extern al capdavant de la companyia té repercussions tant negatives com positives sobre la rendibilitat econòmica d'aquestes. Per a aprofundir en les diferències en relació al CEO de l'empresa familiar segons la generació que dirigeix l'empresa, també s'ha analitzat el Tipus d'estudis del CEO, observant si el CEO de l'empresa posseeix estudis de caràcter econòmic empresarial (valor 1), o si per contra no disposa d'aquests (valor 0 ). Estudis previs suggereixen que l'educació proporciona una major habilitat per a absorbir noves idees i incrementar la capacitat per a processar informació (Hermann i Datta, 2005; Tihanyi et al., 2000; Hitt i Tyler, 1991). No obstant això, en l'empresa familiar s'ha observat una major preferència perquè membres de la família assumeixen posicions de direcció amb independència de si reuneixen o no les habilitats necessàries per fer-ho (Cromie et al., 2001), per la qual cosa l'anàlisi d'aquesta característica resulta especialment interessant en aquest context.

Per a mesurar el creixement empresarial de les empreses i detectar diferències entre generacions, hem tingut en compte tres variables: Creixement de l'actiu, Creixement de l'immobilitzat i Creixement de les vendes. Estudis previs suggereixen que les següents generacions en l'empresa familiar creixen més lentament perquè tenen la tendència a renunciar a part del seu creixement per a no arriscar-se a perdre el control familiar a causa d'un major ús de deute (Molly et al., 2012). De la mateixa manera, altres treballs suggereixen que les empreses familiars de primera generació tenen una major orientació al negoci en comparació amb següents generacions amb major orientació familiar, i que aquesta major orientació al negoci els proporciona una major capacitat de creixement (Cromie et al., 1995; Dunn, 1995; Reid et al., 1999). En aquesta mateixa direcció, McConaughy i Phillips (1999) afirmen que les següents generacions familiars inverteixen menys en equips de capital en I+D. Per contra, altres treballs com el de Zahra (2005) i Fernández i Nieto (2005) troben que a mesura que les noves generacions s'involucren activament en la companyia la riquesa augmenta, suggerint que els nous membres familiars aporten nous coneixements i perspectives a l'empresa, la qual cosa afecta positivament els incentius per a innovar i créixer.

Per a analitzar les diferències en relació a estructura financera, s'han tingut en compte tres variables: Ràtio d'Endeutament, Ràtio de Liquiditat i Variació de l'endeutament. Tradicionalment, la literatura ha reflectit uns menors nivells d'endeutament en les empreses familiars tant a llarg termini (Agrawal i Nagarajan, 1990 
com a curt termini (McConaughy et al., 2001). Un comportament que es justifica per la por a perdre el control de l'empresa en cas de no poder retornar els deutes (Romano et al., 2000). No obstant això, estudis previs suggereixen que poden existir diferències entre empreses familiars depenent de la generació que estigui al capdavant de la mateixa (Molly et al., 2012). Per exemple, Gersick et al. (1997) suggereix que les empreses que han transferit la propietat a la següent generació amb èxit poden obtenir millors condicions financeres per part dels bancs, per la qual cosa es podrien esperar increments de deute superiors amb la incorporació de noves generacions. No obstant això, altres autors suggereixen també que els prestadors poden veure el relleu generacional com una cosa perillosa per a la riquesa de la societat a causa dels problemes d'agència que poden aflorar, a conseqüència de la informació asimètrica entre accionistes i prestamistes (Anderson et al., 2003).

En quant a la internacionalització de l'empresa familiar, s'han inclòs en l'estudi dues variables dicotòmiques que pretenen capturar la propensió de l'empresa a realitzar activitat exterior. La primera, Exporta, pren el valor 1 si l'empresa destina part de les seves vendes a l'exterior, i 0 en cas contrari. Mentre que la segona variable, Importa, pren el valor 1 si l'empresa realitza compres en l'exterior, i 0 en cas contrari. La literatura no és clara respecte a la influència que la generació que dirigeix l'empresa pot exercir sobre la internacionalització de l'empresa familiar. En aquest sentit alguns treballs suggereixen que les noves generacions seran menys propenses a exportar i preferiran centrar-se en mercats interiors (Okoroafo, 1999), mentre que altres estudis suggereixen un efecte positiu amb el relleu generacional (Fernández i Nieto, 2005; Menéndez-Requejo, 2005), la qual cosa suggereix que major recerca sobre aquest tema és necessària.

\section{Resultats}

En la Taula 2 pot observar-se quins són els valors mitjans per al conjunt de la mostra en les diferents variables analitzades, així com quins són aquests valors en el cas de les empreses familiars segons estiguin dirigides per la primera generació o per generacions posteriors. La taula mostra també si a nivell estadístic aquestes diferències observades són estadísticament significatives o no.

En primer lloc, podem observar com les empreses familiars dirigides per la primera generació tendeixen a obtenir uns majors nivells de rendibilitat econòmica $(4.52 \%)$ en comparació amb les empreses dirigides per generacions posteriors (4.06\%). Els menors nivells de rendibilitat associats a generacions posteriors ha estat un resultat habitual en la literatura (McConaughy i Phillips, 1999; Miller et al. 2011; Villalonga i Amit, 2006). Un resultat que justifiquen per la menor qualitat de les relacions entre els administradors familiars en etapes generacionals posteriors, la qual cosa es deu a uns majors nivells de conflicte (Davis i Harveston, 1999; Enseley i Pearson, 2005). Si bé, les nostres dades reflecteixen que aquestes diferències no arriben a ser estadísticament significatives. 
Taula 2. Diferències entre la $1^{\text {a }}$ generació i generacions posteriors.

\begin{tabular}{|l|c|c|c|c|}
\hline \multicolumn{1}{|c|}{ Variable } & $\begin{array}{c}\text { Tota la } \\
\text { mostra }\end{array}$ & 1a generació & $\begin{array}{c}\text { Posteriors } \\
\text { generacions }\end{array}$ & t \\
\hline Rendibilitat econòmica & 4.28 & 4.52 & 4.06 & 1,27 \\
\hline \multicolumn{7}{|c|}{ Característiques del CEO } \\
\hline CEO Extern & 0.0975 & 0.0767 & 0.1166 & $-4,27^{*}$ \\
\hline Estudis empresarials CEO & 0.3134 & 0.2324 & 0.3881 & $-10.79^{*}$ \\
\hline \multicolumn{5}{|c|}{ Creixement Empresarial } \\
\hline Creixement actiu total & 3.57 & 4.29 & 2.92 & $1.86^{*}$ \\
\hline Creixement xifra Vendes & 5.12 & 5.77 & 4.54 & 0.91 \\
\hline Creixement immobilitzat & 9.09 & 9.14 & 9.05 & 0.04 \\
\hline \multicolumn{7}{|c|}{ Estructura financera } \\
\hline Endeutament & 53.65 & 55.70 & 51.78 & $2.93^{*}$ \\
\hline Ràtio Liquiditat & 3.35 & 2.79 & 3.88 & -1.56 \\
\hline Variació Endeutament & 1.51 & 1.31 & 1.70 & $-1.79^{*}$ \\
\hline \multicolumn{7}{|c|}{ Internacionalització } \\
\hline Exporta & 0.2437 & 0.2200 & 0.2658 & $-3.39^{*}$ \\
\hline Importa & 0.2547 & 0.2261 & 0.2811 & $-4.00^{*}$ \\
\hline
\end{tabular}

En canvi, si s'observen diferències significatives entre un i un altre tipus d'empreses en les diferents categories analitzades: Característiques del CEO, Creixement, Estructura financera i internacionalització.

Pel que fa a les característiques del CEO que dirigeix l'empresa, observem com en tots dos casos existeix una clara preferència perquè sigui un membre de la família qui ocupi aquesta posició. No obstant això, mentre en les empreses de primera generació únicament un $7.67 \%$ disposa d'un CEO Extern, aquest percentatge s'incrementa fins al $11.66 \%$ en les empreses de $2 \mathrm{a}$ o posterior generació, sent aquesta diferència estadísticament significativa. Aquest resultat mostra la major predisposició de les següents generacions de posar l'empresa en mans de professionals aliens a la família. Si bé, també es pot deure a la dificultat de trobar un relleu amb les habilitats necessàries en el si familiar. D'una manera semblant, i segurament vinculat al resultat anterior, també s'observa que en posteriors generacions el CEO de l'empresa tendeix a posseir en major proporció estudis econòmic-empresarials. Aquest resultat s'explicaria per la major preparació acadèmica que solen posseir les noves generacions, així com per aquesta major propensió a contractar un CEO professional extern a la família. És de destacar, no obstant això, que per al conjunt de la mostra s'observa que únicament el $31.34 \%$ dels CEO posseeixen estudis universitaris de caràcter econòmic-empresarial, mentre que dues terceres parts de la mostra manquen d'aquesta formació.

També s'han observat algunes diferències estadísticament significatives entre tots dos grups d'empreses en relació a les seves polítiques d'inversió i creixement. Observem com les empreses familiars dirigides per la primera generació tendeixen a créixer a un major ritme que les empreses dirigides per generacions posteriors, almenys en el que a volum d'actiu es refereix (4.29\% anual per $2.92 \%$ anual). Aquest resultat, podria entendre's pel fet que quan les empreses són joves tenen un major potencial de creixement, no obstant això, quan les noves generacions assumeixen el control ja es troben amb unes empreses consolidades a les quals els costa més créixer, alguna cosa que sens dubte estaria lligat al cicle de vida de l'empresa. A més, autors com Kellermans 
i Eddleston (2004) i Blanco-Mazagatos et al. (2007) suggereixen que amb les noves generacions augmenta l'asimetria en la informació entre propietaris i gestors, la qual cosa es tradueix en conflictes, rivalitat i oportunisme empresarial, podent ser perjudicial per al creixement de l'empresa. De la mateixa manera, en analitzar el creixement del volum de facturació i de les inversions en actiu fix, també observem un major creixement mentre la primera generació està al capdavant de la companyia, no obstant això, les diferències en aquesta ocasió no arriben a ser estadísticament significatives entre tots dos grups.

En quant a l'estructura financera de l'empresa, s'observa que les següents generacions tendeixen a presentar, i d'una manera estadísticament significativa, uns nivells d'endeutament significativament inferiors als de la primera generació $(55.70 \%$ per $51.78 \%$ ), la qual cosa faria pensar en una major aversió al risc per part d'aquests dirigents. No obstant això, cal tenir en compte que aquest tipus d'empreses mostra una clara preferència per l'autofinançament mitjançant la retenció de beneficis, per la qual cosa amb el pas dels anys l'acumulació de beneficis podria explicar aquests menors nivells d'endeutament. Precisament, una menor aversió al risc per part de les noves generacions quedaria descartada si tenim en compte que els resultats mostren que tendeixen a experimentar uns majors increments anuals d'endeutament, si bé en aquesta ocasió les diferències no resulten estadísticament significatives. El cert és que la literatura no és unànime sobre aquesta qüestió, amb treballs que justifiquen menors nivells de deute en les següents generacions (Schulze et al. 2001; Kaye i Hamilton, 2004; Reid et al., 1999) mentre uns altres argumenten un endeutament superior per a aquestes (Blanco-Mazagatos et al., 2007).

Finalment, pel que fa a les polítiques d'internacionalització, s'observen diferències significatives tant en relació a la propensió a exportar com a la propensió a importar, sent major aquesta tendència a la internacionalització en les empreses familiars dirigides per segones o posteriors generacions. Alguns estudis suggereixen que les noves generacions disposen de les capacitats de les quals manca el fundador, $i$ en conseqüència estan oberts a noves idees i estratègies, per la qual cosa poden ser desencadenants de la cerca d'oportunitats empresarials internacionals (Mitter et al., 2014). Aquest resultat, per tant, està en línia amb diferents treballs previs que van trobar una relació positiva entre la incorporació de noves generacions i la internacionalització de l'empresa familiar (Fernández i Nieto, 2005; Menéndez-Requejo, 2005; Calabrò i Mussolino, 2011).

\section{Discussió i conclusions}

Si bé els resultats mostren que no existeixen diferències estadísticament significatives en quant a rendibilitat entre empreses de primera generació i posteriors, si han mostrat l'existència de diferències significatives en relació a altres dimensions de la gestió de l'empresa familiar. Unes diferències que, en un sentit o un altre, si afecten a la rendibilitat de les empreses familiars, els propietaris de les quals haurien de tenir en compte en la gestió de les mateixes per a millorar els seus resultats.

Per exemple, s'han observat diferències en relació a les característiques del CEO que dirigeix l'empresa, observant-se com si bé en tots dos grups d'empreses predominen els CEOs familiars, en segones i posteriors generacions hi ha una major presència de CEOs professionals externs. També, en posteriors generacions s'observa que un major número de CEOs compta amb una formació específica en l'àmbit econòmic-empresarial. 
En relació al creixement empresarial, s'ha observat que aquest tendeix a ser superior en les primeres generacions, tant en relació al creixement de l'actiu, de l'immobilitzat com de la facturació. Si bé, les diferències únicament són significatives en relació al creixement de l'actiu total. Estudis previs suggereixen que les següents generacions en l'empresa familiar creixen més lentament perquè tenen la tendència a renunciar a part del seu creixement per a no arriscar-se a perdre el control familiar a causa d'un major ús de deute (Molly et al., 2012), mentre que altres treballs suggereixen que aquest major creixement en la primera generació es deu a la seva major orientació al negoci, en contraposició a la següents generacions, amb major orientació familiar (Cromie et al., 1995; Dunn, 1995 i Reid, 1999). La literatura prèvia suggereix que un major creixement empresarial repercuteix en uns majors nivells de rendibilitat econòmica, un factor especialment a tenir en compte, si considerem les restriccions al creixement que tradicionalment sofreixen les empreses familiars, la qual cosa estaria limitant també la seva rendibilitat. És per això que les noves generacions han de trobar vies perquè l'empresa pugui continuar creixent en el futur, ja sigui trobant nous mercats o invertint en $\mathrm{I}+\mathrm{D}+\mathrm{i}$, perquè d'això dependrà la seva rendibilitat futura.

En quant a l'estructura financera de l'empresa familiar, els resultats mostren que, si bé els nivells d'endeutament són superiors en les empreses de primera generació, l'increment d'aquests nivells és superior en generacions posteriors. Gersick et al. (1997) van suggerir que les empreses que han transferit la propietat a la següent generació amb èxit poden obtenir millors condicions financeres per part dels bancs, la qual cosa podria explicar aquest major increment en els nivells de deute en següents generacions.

També s'han observat diferències pel que fa a la internacionalització de l'empresa familiar segons la generació que la dirigeixi. Per part de les generacions posteriors, s'ha observat una major propensió tant a la importació com a l'exportació, sent les diferències estadísticament significatives entre tots dos grups d'empreses. Cal tenir en compte que les empreses es veuen obligades a la internacionalització de les seves activitats a causa de l'estretor dels mercats locals i a la necessitat de reduir costos mitjançant la consecució d'economies d'escala (Cavis, 1996). En empreses familiars, si l'exportació té èxit es considera una activitat que augmenta la capacitat productiva i la xifra de negocis, la qual cosa permet augurar un més bon futur per a la companyia i, per tant, al patrimoni familiar (Claver et al., 2007). Per tant, és necessari que les empreses familiars facin aquest esforç d'internacionalització, especialment en les primeres generacions, tradicionalment més centrades en els mercats locals i poc inclinades a internacionalitzar-se pels riscos que aquesta estratègia comporta.

En resum, si bé els resultats no han mostrat l'existència de diferències significatives en quant a rendibilitat entre empreses familiars de primera generació i empreses familiars de generacions posteriors, si han mostrat que tots dos grups d'empreses presenten unes característiques pròpies en la gestió que posteriorment tindran incidència en la rendibilitat. Per això, coneixent les febleses i fortaleses revelades en aquest estudi per a tots dos tipus d'empresa, hauria de ser més senzill identificar en quins àmbits de la gestió poden millorar les unes i les altres a fi d'incrementar la seva rendibilitat. Aquest estudi, per tant, té interessants implicacions pràctiques perquè assenyala algunes de les opcions que tenen les empreses familiars per a millorar la seva rendibilitat, però distingint en quins aspectes específics poden actuar les empreses de primera generació i en quins aspectes poden actuar les empreses dirigides per generacions posteriors per a aconseguir-ho. Perquè com es desprèn de l'anàlisi realitzada, l'empresa familiar no 
constitueix un grup homogeni d'empreses, sinó que podem identificar subgrups amb característiques particulars que han de ser analitzades d'una manera específica.

Donada l'evident heterogeneïtat de l'empresa familiar, futures línies de recerca hauran de passar per una anàlisi més detallada del funcionament dels diferents tipus d'empresa familiar, distingint no sols la generació propietària, sinó la concentració de la propietat, el tipus de CEO o el sector en el qual operen, perquè tots ells són elements que condicionen el funcionament d'aquest tipus d'empreses, el que impedeix que puguin continuar sent analitzades com un grup homogeni d'empreses.

\section{Referències}

Agrawal, A. i Nagarajan, N.J. (1990). Corporate capital structure, agency costs, and ownership control: the case of all-equity firms. The Journal of Finance, 45(4), 13251331.

Anderson, C. R. i Reeb, M. D. (2003). Founding-family ownership and firm performance: Evidence from the S\&P500. The Journal of Finance, 58(3), 1301-1328.

Benavides-Velasco, C.A.; Quintana-García, C. i Guzmán-Parra, V.F. (2013). Trends in family business research. Small Business Economics, 40, 41-57.

Blanco-Mazagatos, V.; de Quevedo-Puente, E. i Castrillo, L.A. (2007). The trade-off between financial resources and agency costs in the family business: An exploratory study. Family Business Review, 20(3), 199-213.

Cadbury, A (2002). Corporate Governance and Chairmanship. A Personal View. Oxford University Press.

Calabrò, A, Mussolino, D. i Huse, M. (2009). The role of board of directors in the internationalization process of small and medium sized family businesses. International Journal of Globalization and Small Business, 3(4), 393-411.

Caves, R.E. (1996). Multinational Enterprise and Economic Analysis; Harvard University Press: Boston, MA, USA

Chami, R. (1999). What is different about family businesses? Notre Dame University and International Monetary Fund Institute, Working Paper 01/70.

Claver, E.; Rienda, L. i Quer, D. (2007). The internationalisation process in family firms: Choice of market entry strategies. Journal of General Management, 33, 1-14.

Cromie, S.; Dunn, B.; Sproull, A. i Chalmers, D. (2001). Small firms with a family focus in the Scottish Highlands and Islands. The Irish Journal of Management, 22(2), 45-66.

Cromie, S.; Stephenson, B. i Montieth, D. (1995). The management of family firms: An empirical investigation. International Small Business Journal, 13, 11-34.

Davis, P. S. i Harveston, P. D. (1999). In the founder's shadow: Conflict in the family firm. Family Business Review, 12(4), 311-323.

De Clercq, D. i Belausteguigoitia, I. (2015). Intergenerational strategy involvement and family firms' innovation pursuits: The critical roles of conflict management and social capital. Journal of Family Business Strategy, 6(3), 178-189.

Dunn, B. (1995). Success themes in Scottish family enterprises: Philosophies and practices through generations. Family Business Review, 8(1), 17-28. 
Ensley, M. D. i Pearson, A. W. (2005). A comparison of the behavioral processes of top management teams in family and non-family firms: Cohesion, conflict, potency, and consensus. Entrepreneurship: Theory and Practice, 29(3), 267-284.

Fang, H.; Kotlar, J.; Memili, E.; Chrisman, J.J. i De Massis, A. (2018). The pursuit of international opportunities in family firms: Generational differences and the role of knowledge-based resources. Global Strategy Journal, 8(1), 136-157.

Fernández, Z. i Nieto, M.J. (2005). Internationalization strategy of small and mediumsized family businesses: Some influential factors. Family Business Review, 18(1), 7789.

Finkelstein, S. i Hambrick, D. (1996) StrategicLeadership: Top Executives and Their Effects on Organizations. Minneapolis-St. Paul: West.

Galve-Gorriz, C. i Salas-Fumas, V. (2011). Growth strategies, professionalization, ownership structure and performance across generations of a family firm. African Journal of Business Management, 5(9), 3589-3604.

Gersick, K.; Davis, J.; Hampton, M. i Lansberg, I. (1997). Generation to generation: Life cycles of the family business. Boston, MA: Harvard Business School.

Herrmann, P. i Datta, D. K. (2005). Relationship between top management team characteristics and international diversification: An empirical investigation. British Journal of Management, 16(1), 69-78.

Hitt, M. i Tyler, B. (1991). Strategic Decision Models: Integrating Different Perspectives. Strategic Management Journal, 12, 327-351.

Instituto de la Empresa Familiar (2015). La Empresa Familiar en España. Editado por $I E F$.

Instituto de la Empresa Familiar (2018). Factores de competitividad y análisis financiero en la empresa familiar. Editado por IEF.

Jaffe, D.T. i Lane, S.H. (2004). Sustaining a family dynasty: Key issues facing complex multigenerational Business-and Investment-Owning Families. Family Business Review, 17(1), 81-98.

Jensen, M. i Meckling, W. (1976). Theory of the Firm: Managerial Behavior, Agency Costs and Ownership Structure. Journal of Financial Economics, 3, 305-360.

Kaye, K. i Hamilton, S. (2004). Roles of trust in consulting to financial families. Family Business Review, 17(2), 151-163.

Kellermanns, F.W. i Eddleston, K.A. (2004). Feuding families: When conflict does a family firm good. Entrepreneurship Theory and Practice, 28(3), 209-228.

Lansberg, I. (1999). Succeeding generations. Boston, MA: Harvard. Business School Press.

Levring, R. i Moskowitz,M. (1993). The ten best companies to work for in America. Business and Society Review, 85, 26-38.

McConaughy, D. i Phillips, G. (1999). Founders versus descendants: The profitability, efficiency, growth characteristics, and financing in large, public, foundingfamilycontrolled firms. Family Business Review, 12(2), 123-132.

McConaughy, D.L.; Matthews, C.H. i Fialko, A.S. (2001). Founding family controlled firms: performance, risk, and value. Journal of Small Business Management, 39 (1), 31- 
49.

McCourt D.M. (2012) The "Problem of Generations" Revisited: Karl Mannheim and the Sociology of Knowledge in International Relations. In: Steele B.J.; Acuff J.M. (eds) Theory and Application of the "Generation" in International Relations and Politics. Palgrave Macmillan, New York

Menéndez-Requejo, S. (2005). Growth and internationalization of family businesses. International Journal of Globalisation and Small Business, 1, 122-133.

Miller, D.; Steier, L. i Le Breton-Miller, I. (2003). Lost in time: intergenerational succession, change, and failure in family business. Journal of Bussiness Venturing 18 (4), 513-531.

Miller, D.; Breton-Miller, L. i Lester, R. H. (2011). Family and lone founder ownership and strategic behaviors: Social contexts, identity, and institutional logics. Journal of Management Studies, 48(1), 1-25.

Mitter, C.; Duller, C.; Feldbauer-Durstmüller, B. i Kraus, S. (2014). Internationalization of family firms: The effect of ownership and governance. Review of Managerial Science, 8, 1-28.

Molly, V.; Laveren, E. i Jorissen, A. (2012). Intergenerational differences in family firms: Impact on capital structure and Growth Behavior. Entrepreneurship Theory and Practice, 36(4), 703-725.

Okorafo, S. C. (1999). Internationalization of family businesses: Evidence from Northwest Ohio, USA. Family Business Review, 12(2), 147-158.

Poza (1988). Managerial practices that support intrepreneurship and continued growth. Family Business Review, 1(4), 339-359.

Reid, R.; Dunn, B.; Cromie, S. i Adams, J. (1999). Family orientation in family firms: A model and some empirical evidence. Journal of Small Business and Enterprise Development, 6(1), 55-66.

Romano, C.A.; Tanewski, G.A. i Smyrnios, K.X. (2000). Capital structure decision making: a model for family business. Journal of Business Venturing, 16(3), 285-310.

Sánchez, L.; Gallizo, J.L. i Moreno, J. (2019). The influence of the CEO in listed family businesses. Intangible Capital, 15(2), 128-142.

Seymour, K.C. (1993) Inter-generational Relationships in the Family Firm: the Effect on Leadership Succession. Family Business Review, 6 (3), 263-281.

Schulze, W.S.; Lubatkin, M.H.; Dino, R.N. i Bucholtz, A.K. (2001). Agency relationships in family firms: Theory and evidence. Organization Science, 12(2), 99116.

Shi, H.; Graves, C. i Barbera, F. (2019) Intergenerational succession and internationalisation strategy of family SMEs: Evidence from China. Long Range Planning, 52(4), 1-18.

Tihanyi, L.; Elistrand, A.; Daily, C. i Dalton, D. (2000). Composition of the top management team and firm international diversification. Journal of Management, 26(6), $1157-1177$

Villalonga, B. i Amit, R. (2006). How do family ownership, control and management affect firm value? Journal of Financial Economics, 80, 385-417. 
Williams, D.; Zorn, M.; Crook T. i Combs, J. (2013). Passing the Torch: Factors Influencing Transgenerational Intent in Family Firms. Family Business Review, 62(3), 415-428.

Woodfield, P. i Husted, K. (2019). How does knowledge sharing across generations impact innovation? International Journal of Innovation Management, 23(8).

Yu, J. i Cai, X. (2017). The Influence of Intergenerational Succession of Family Business on Its Performance-Taking Enterprise Innovation as a Mediating Variable. American Journal of Industrial and Business Management, 7(06), 798-815.

Zahra, S.A. (2005). Entrepreneurial risk taking in family firms. Family Business Review, 18(1), 23-40. 